\begin{tabular}{l} 
Sharif University of Technology \\
Scientia Iranica \\
SCIENTIA \\
IRAN \\
Thansactions A: Civil Engineering \\
\hline
\end{tabular}

\title{
Probabilistic seismic demand assessment of steel moment-resisting frames with mass irregularity in height
}

\author{
N. Fanaie ${ }^{a, *}$ and M.S. Kolbadi ${ }^{b}$ \\ a. Department of Civil Engineering, K. N. Toosi University of Technology, Tehran, Iran. \\ b. Department of Civil Engineering, Isfahan (Khorasgan) Branch, Islamic Azad University, Isfahan, Iran. \\ Received 11 January 2017; received in revised form 26 June 2017; accepted 11 September 2017
}

\author{
KEYWORDS \\ Steel moment- \\ resisting frame; \\ Mass irregularity; \\ Response modification \\ factor; \\ Incremental dynamic \\ analysis; \\ Probabilistic seismic \\ demand analysis.
}

\begin{abstract}
Ductility with direct effect on the response modification factor of buildings can influence their seismic performance. Moreover, some factors, such as geometry and different types of irregularity, can affect the ductility and seismic performance of structures. In this study, the effects of mass irregularity in height on the overstrength, ductility, response modification factors, and probabilistic seismic performance in steel Moment-Resisting Frames (MRFs) are assessed. Then, the obtained results are compared with those of regular structures. For this purpose, Incremental Dynamic Analysis (IDA) is implemented using ten records out of past worldwide earthquakes. The location of mass concentration in height is studied by assessing 8-, 12-, and 16-storey buildings with their mass concentrated at the first floor, mid-height and roof. Then, the probabilistic seismic responses of these structures are evaluated using the outputs of IDA. In this regard, probabilistic seismic demand analysis is conducted on each model. The obtained results are used to plot the seismic fragility and demand curves for both regular and irregular models. Based on the findings, mass irregularity causes the reduction of ductility and response modification factors. This effect increases when the heavier storey is located either in the first floor or in the roof. Moreover, mass irregularity brings about an increase in probability of damage occurrence or its exceeding a certain level.
\end{abstract}

(C) 2019 Sharif University of Technology. All rights reserved.

\section{Introduction}

ATC-3-06 [1] has established a basis in Earthquake Engineering in the United States and introduced new concepts, such as applying response modification factor $(R)$ to the seismic codes. This factor is used to reduce the values of design forces recommended with respect to the risk evaluation and nonlinear behaviour

\footnotetext{
*. Corresponding author.

E-mail addresses: fanaie@kntu.ac.ir (N. Fanaie);

Ams.kolbadi@yahoo.com (M.S. Kolbadi)
}

doi: $10.24200 /$ sci. 2017.4468 of the structure [2]. In fact, response modification factor includes inelastic performance of the structure, indicating its hidden strength in inelastic stage. This factor has been defined for the first time in ATC-306 [1] based on the concepts, such as ductility factor, overstrength factor, and degree of uncertainty, and then has been modified in ATC-19 [1] and ATC34 [3]. Response modification factor of the building is affected by the ductility influential factors, such as lateral load-resisting system and structure's geometry. However, the effects of the mentioned influential factors have not been considered in the seismic codes. Therefore, the geometry of structure should be scientifically investigated so as to consider its effect 
on the determination of response modification factor. The existing buildings have been constructed with respect to different objectives and applications. All these factors may cause irregularities in the structures. According to the seismic codes, the structures are classified into regular and irregular ones in terms of height and plan. Non-geometric vertical irregularity can occur in the buildings with irregular distribution of mass, strength, or lateral stiffness [4]. The empirical relationships presented to determine the fundamental period of structure depend upon the type and height of structure. The irregularity effects are not considered in the mentioned relations. Weak parts of structures very often experience the aftermath of earthquakes due to rapid changes of stiffness, strength or ductility [5]. The effects of earthquakes on such vulnerable points become more prominent in the irregular distribution of effective masses [4]. The irregular structures, compared to regular ones, received more damages in the past earthquakes [6].

This study focuses on the effects of mass irregularity as well as irregular distribution of mass in height on the response modification, ductility, and overstrength factors. Moreover, probabilistic seismic demand analysis of the irregular buildings is conducted to evaluate reliability of their behaviors with respect to the inherent uncertainties in the earthquake. For this purpose, the fragility curves are plotted for regular and irregular structures to identify the occurrence probability of the limit states, defined in seismic code for intensity index levels. So far, various studies have been carried out on the performance of irregular buildings in height. Valmudsson and Nau [7] investigated mass, stiffness, and strength irregularities, and found that the responses of irregular structures might be estimated incorrectly by the equivalent lateral force procedure. Al-Ali and Krawinkler [8] studied the effects of mass, stiffness, and strength irregularities on the performance of 10-storey buildings. According to their results, the performance of structure was affected more significantly by the irregularity of strength, as compared to that of stiffness. Moreover, the combination of these two irregularities is still more effective than mass irregularity. Tremblay and Poncet [9] evaluated seismic responses of the frames with vertical mass irregularities. They designed the frames according to NBCC provisions using static and dynamic analyses. Similar values were obtained from static and dynamic analyses for storey drifts (as prescribed by NBCC provisions), indicating that they have no consequential role in predicting the effects of mass irregularity. Kim and Hong [10] investigated collapse-resisting capacity in the building models with the stiffness and strength irregularities. The irregularities were created by removing the column from the intermediate storey. According to the obtained results, collapse potential of regular structure was slightly different from that of irregular one. Pirizadeh and Shakib [4] assessed the effects of non-geometric vertical irregularities on the seismic performance of steel MRFs. They considered their limit-state capacities and used probabilistic performance-based approach. According to their research, non-uniform distribution of lateral load-resisting properties in the height has significant effect on the seismic performance of the structure, especially at the limit-states close to collapse up to global dynamic instability. Vertical irregularities may affect seismic intensity and/or ductility capacity of structures, considering their types and positions. Moreover, mean annual frequency of global dynamic instability performance increases by $5-30 \%$ owing to the vertical irregularities.

\section{The Studied structures}

\subsection{Reference regular structures}

In this study, 8-, 12-, and 16-storey regular steel structures with intermediate MRFs are considered as benchmarks. The structures are three dimensionally designed according to Iranian Seismic Code [11] and Iranian National Building Code (part 10) [12], based on the provisions which are very similar to those of AISC [13] and FEMA 350 [14]. They are designed with the response modification factor $(R)$ of 7 [11] for a very high seismic zone with a site-specific earthquake acceleration of $0.35 \mathrm{~g}$ (Tehran), according to the Iranian Seismic Code [11]. Buildings are located on soil type II based on Iranian Seismic Code [11] site classification, in which the average shear wave velocity to a depth of $30 \mathrm{~m}$ is $360-750 \mathrm{~m} / \mathrm{s}$.

Figure 1 presents the plan of the studied structures. The height of $3 \mathrm{~m}$ is considered for each storey; each frame has 3 spans with the length of $5 \mathrm{~m}$; the applied steel is ST-37-1 (equivalent to the steel S235 of standard EN10025) with a yield stress of $235 \mathrm{MPa}$. The dead and live loads of all floors are $600 \mathrm{~kg} / \mathrm{m}^{2}$ and

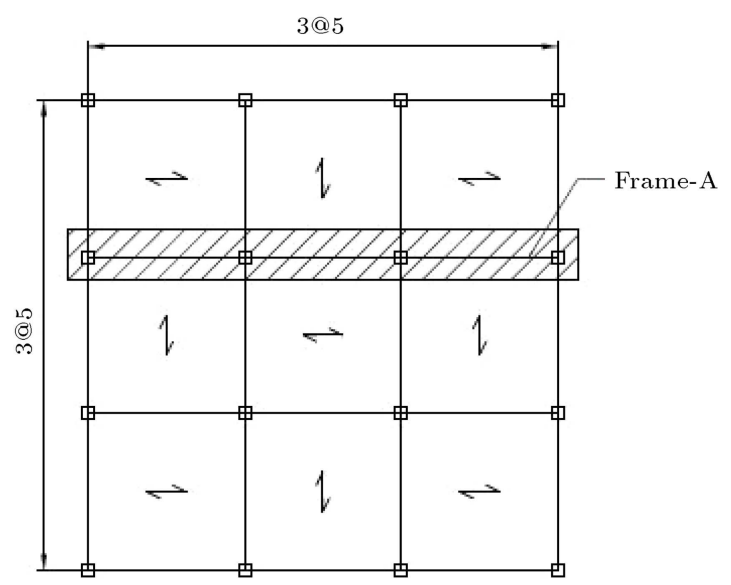

Figure 1. Plan of studied models (3 spans in each direction). 
$200 \mathrm{~kg} / \mathrm{m}^{2}$, respectively, and the live load of roof is $150 \mathrm{~kg} / \mathrm{m}^{2}$. Table 1 presents the cross-sections of all members of the studied model.

\subsection{Irregular structures}

According to different codes, sudden changes in mass of a storey can cause mass irregularity. In this survey, mass irregularity is evaluated considering three differ- ent heights, namely first floor, mid-height, and roof. Accordingly, a factor is applied to the mass of a storey such that the difference between its mass and that of the adjacent storey is more than $150 \%$ based on UBC97 [15]. Finding the locations of mass concentration in different heights and comparing them with those of regular models could be effective in understanding the seismic behavior of mass irregular structures.

Table 1. Cross-sections of all members of the studied model.

\begin{tabular}{|c|c|c|c|c|c|c|}
\hline Storey no. & & Beam & Column & & Beam & Column \\
\hline 1 & \multirow{8}{*}{ 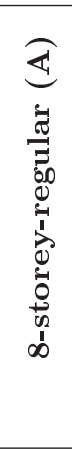 } & IPE450 & TUBE $350 \times 20$ & \multirow{8}{*}{ 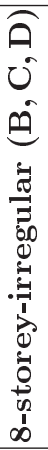 } & IPE450 & TUBE $400 \times 20$ \\
\hline 2 & & IPE450 & TUBE $350 \times 20$ & & IPE450 & TUBE $350 \times 20$ \\
\hline 3 & & IPE450 & TUBE $300 \times 20$ & & IPE450 & TUBE $300 \times 20$ \\
\hline 4 & & IPE450 & TUBE $300 \times 20$ & & IPE450 & TUBE $300 \times 20$ \\
\hline 5 & & IPE400 & TUBE $300 \times 20$ & & IPE400 & TUBE $300 \times 20$ \\
\hline 6 & & IPE400 & TUBE $300 \times 15$ & & IPE400 & TUBE $300 \times 15$ \\
\hline 7 & & IPE330 & TUBE $300 \times 15$ & & IPE330 & TUBE $300 \times 15$ \\
\hline 8 & & IPE330 & TUBE $200 \times 15$ & & IPE330 & TUBE $200 \times 15$ \\
\hline 1 & \multirow{12}{*}{ 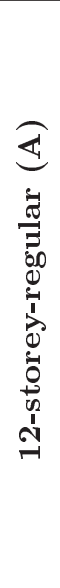 } & IPE450 & TUBE $500 \times 25$ & \multirow{12}{*}{ 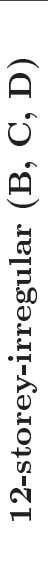 } & IPE450 & TUBE $500 \times 25$ \\
\hline 2 & & IPE450 & TUBE $500 \times 25$ & & IPE450 & TUBE $500 \times 25$ \\
\hline 3 & & IPE450 & TUBE $450 \times 20$ & & IPE450 & TUBE $450 \times 20$ \\
\hline 4 & & IPE450 & TUBE $450 \times 20$ & & IPE450 & TUBE $450 \times 20$ \\
\hline 5 & & IPE450 & TUBE $450 \times 20$ & & IPE450 & TUBE $450 \times 20$ \\
\hline 6 & & IPE450 & TUBE $400 \times 20$ & & IPE450 & TUBE $400 \times 20$ \\
\hline 7 & & IPE400 & TUBE $400 \times 20$ & & IPE400 & TUBE $400 \times 20$ \\
\hline 8 & & IPE400 & TUBE $400 \times 20$ & & IPE400 & TUBE $400 \times 20$ \\
\hline 9 & & IPE400 & TUBE $300 \times 20$ & & IPE400 & TUBE $300 \times 20$ \\
\hline 10 & & IPE400 & TUBE $300 \times 20$ & & IPE330 & TUBE $300 \times 20$ \\
\hline 11 & & IPE330 & TUBE $300 \times 20$ & & IPE330 & TUBE $300 \times 20$ \\
\hline 12 & & IPE330 & TUBE $200 \times 15$ & & IPE330 & TUBE $200 \times 15$ \\
\hline 1 & \multirow{16}{*}{ 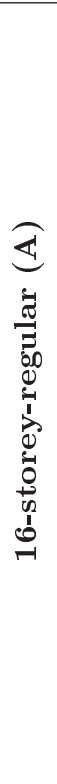 } & IPE450 & TUBE $500 \times 25$ & \multirow{16}{*}{ 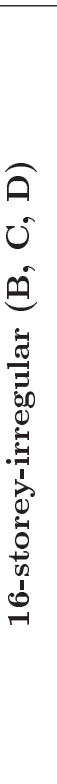 } & IPE450 & TUBE $500 \times 25$ \\
\hline 2 & & IPE450 & TUBE $500 \times 25$ & & IPE450 & TUBE $500 \times 25$ \\
\hline 3 & & IPE450 & TUBE $500 \times 25$ & & IPE450 & TUBE $500 \times 25$ \\
\hline 4 & & IPE450 & TUBE $450 \times 25$ & & IPE450 & TUBE $450 \times 25$ \\
\hline 5 & & IPE450 & TUBE $450 \times 25$ & & IPE450 & TUBE $450 \times 25$ \\
\hline 6 & & IPE450 & TUBE $450 \times 25$ & & IPE450 & TUBE $450 \times 25$ \\
\hline 7 & & IPE400 & TUBE $450 \times 25$ & & IPE450 & TUBE $450 \times 25$ \\
\hline 8 & & IPE400 & TUBE $450 \times 25$ & & IPE450 & TUBE $450 \times 25$ \\
\hline 9 & & IPE400 & TUBE $450 \times 25$ & & IPE400 & TUBE $450 \times 25$ \\
\hline 10 & & IPE400 & TUBE $400 \times 20$ & & IPE400 & TUBE $400 \times 20$ \\
\hline 11 & & IPE400 & TUBE $400 \times 20$ & & IPE400 & TUBE $400 \times 20$ \\
\hline 12 & & IPE400 & TUBE $400 \times 20$ & & IPE400 & TUBE $400 \times 20$ \\
\hline 13 & & IPE360 & TUBE $400 \times 20$ & & IPE360 & TUBE $400 \times 20$ \\
\hline 14 & & IPE360 & TUBE $350 \times 20$ & & IPE360 & TUBE $350 \times 20$ \\
\hline 15 & & IPE330 & TUBE $350 \times 20$ & & IPE330 & TUBE $350 \times 20$ \\
\hline 16 & & IPE330 & TUBE $350 \times 20$ & & IPE330 & TUBE $350 \times 20$ \\
\hline
\end{tabular}




\subsection{Modeling}

A central frame of each structure is modelled twodimensionally in OpenSees program (frame A in Figure 1). It should be mentioned that torsional effects caused by the earthquakes are out of the scope of this research. Meanwhile, much less time is needed for the analysis, and a two-dimensional model can present sufficiently accurate results of regular and irregular MRFs with and without torsional effects. Figure 2(a) and (b) illustrates regular and irregular 2D frames as well as different positions of irregular storey. Nonlinear beam column element is employed to model the beam and column in the nonlinear deformation range. This element is used to consider the effects of $P-\Delta$ and
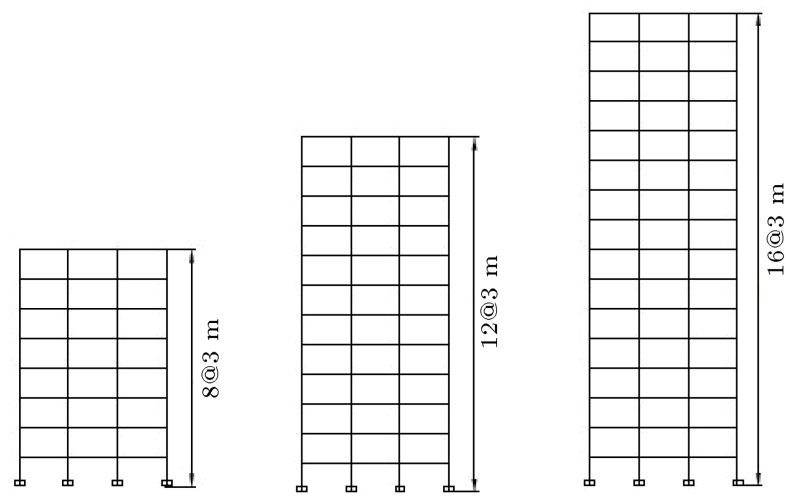

(a)
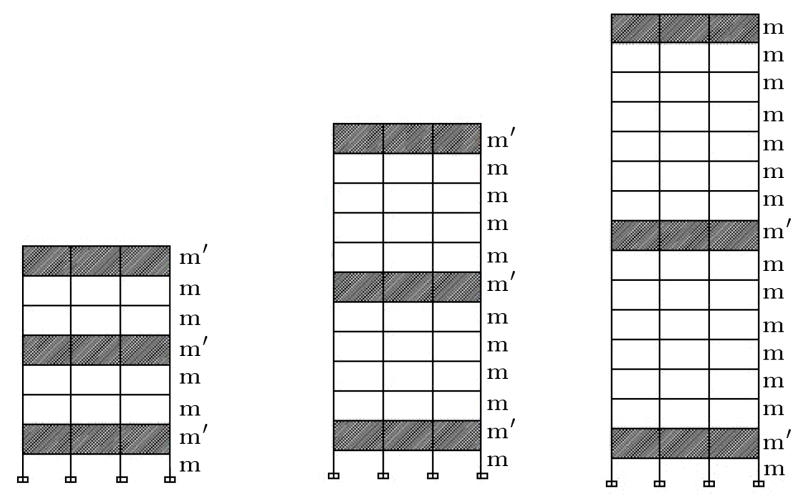

$\left(1.5 \mathrm{~m}<\mathrm{m}^{\prime}<2 \mathrm{~m}\right)$

(b)

Figure 2. 2D studied models: (a) Regular storey, and (b) different positions of irregular storey. large deformations and, subsequently, the geometrical nonlinear effects of the model. Each element, including beam and column, is divided into several fibres along their sections and several segments along their lengths to model distributed plasticity in their lengths (see Figure 3(a) and (b) [16].

This study used one force-based element with 10 Lobito integration scheme points and $P-\Delta$ transformation for each beam/column member. Each box section is discretized into 30 fibers. Both types of nonlinearities, namely geometrical and material, are dealt with in this research. Furthermore, to take into account the $P-\Delta$ effects of the gravity frames on seismic response of the frames, a dummy column is modeled. In other words, half of total gravity load of each floor is applied to the dummy column.

Behavior of the beam-to-column connections has a significant role in the structural response of steel MRFs. To design a structure to withstand certain earthquake load, the optimum system of beam-tocolumn connections is the best option so that the structure can develop the minimum possible base shear as well as small lateral deformations. Nader and Astaneh Asl [17] studied experimentally the behavior of simple and semi-rigid structures under dynamic loading and compared their response to that of the rigid structure subjected to similar earthquakes. They observed that moment capacity of the semi-rigid connections was higher than expected. Based on Nader and Astaneh Asl research [17], flexible and semi-rigid structures demonstrated remarkable potential to resist earthquake loading.

In spite of providing cost-effectiveness, PartiallyRestrained (PR) connection systems are not currently certified to be utilized for steel MRFs. Two partiallyrestrained bolted connections of beam to column (with angle and T-stub) were studied numerically, and their potential uses in the steel MRFs were studied by Brunesi et al. [18,19]. Failure mechanisms, the displacement ductility capacity, and dissipation energy capabilities of these partially-restrained connections are studied, and it is concluded that these types of connections can be conspicuously applicable to steel MRFs $[18,19]$.

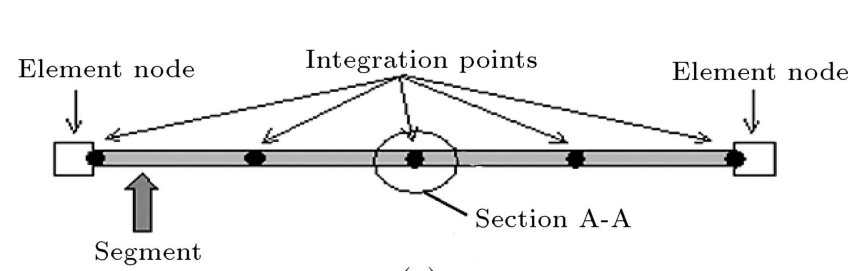

(a)

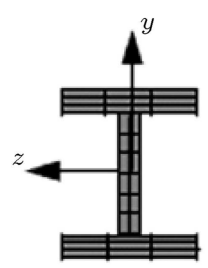

Section A-A

(b)

Figure 3. Dividing the element and section in OpenSees: (a) Dividing the element into several segments and (b) dividing the section into fibers [14]. 


\section{Methodology}

The values of overstrength, ductility, and response modification factors are calculated for regular and irregular structures using Incremental Dynamic Analysis (IDA). Besides, the probabilistic seismic behaviors of the structures are assessed through Probabilistic Seismic Demand Analysis (PSDA). IDA is one of the most powerful methods capable of covering the behavior of structure from elastic limit to collapse state. In this method, which includes nonlinear dynamic analysis, the accelerograms are scaled to assess the behavior of structure from linearly elastic to collapse state. In this regard, an appropriate number of earthquake records should be used to study the uncertainty existing in the frequency content and spectral shapes of earthquakes. Each earthquake record is scaled so that it can include a considerable range of seismic intensities and the behavior of the structure from elastic limit to collapse state [20]. It is essential to select the appropriate parameters of Intensity Measure (IM) as well as Damage Measure (DM) for IDA analysis. Besides the scalability of the selected intensity measure, dynamic characteristics of the records, frequency content, energy, etc. should also be considered in choosing such IM. A couple of scalable parameters are Peak Ground Acceleration (PGA), Peak Ground Velocity (PGV) and spectral acceleration corresponding to the first mode $\left(S a\left(T_{1}\right)\right)[20]$. The latter is used as the intensity measure in this study. Damage Measure $(\mathrm{DM})$ is derived from the output of nonlinear dynamic analysis. Maximum base shear, node rotation, interstorey drift, and axial deformation of the elements can be considered as the damage measure criteria. The selection of damage measure depends on the application of structure. In this study, maximum interstorey drift ratio $\left(\theta_{\max }\right)$ is used as DM to meet the best behavior of structure [20].

\section{Choosing and scaling the accelerograms}

A proper number of earthquake records are selected to determine the bearing capacity of structure up to collapse state and to perform nonlinear time history analysis. These records should demonstrate the seismic level of the site. In addition, site conditions and soil type have significant effects on the frequency content of earthquake records [20,21]. The records considered in this research are adopted from NEHRP site class C with respect to the soil type of the site. Table 2 presents the characteristics of the mentioned records. A suitable algorithm is employed to scale the seismic intensity measure to achieve the optimum number of records for analysis. This algorithm should have sufficient accuracy and speed in scaling the seismic intensity up to collapse of structure. In the current research, hunt and fill algorithm [21] is applied to optimize the number of scaling for each record. It is explained in detail in Section 7.

\section{Limit states}

The standard codes suggest various criteria for damage definition in different limit states. In FEMA 350 [14], limit states are identified according to the heights of Ordinary Moment-Resisting Frames (OMRF) and Special Moment-Resisting Frames (SMRF) in the performance levels of Immediate Occupancy (IO) and Collapse Prevention (CP) limit-states. In the abovementioned code, the 16-storey frame is classified to be high rise, and 8- and 12-storey frames are classified as mid-rise structures. Accordingly, the values of inter-storey drift ratio in the mid-rise buildings for OMRF and SMRF are considered as $1 \%$ and $2 \%$ in IO, respectively, and $8 \%$ and $10 \%$ in $\mathrm{CP}$, respectively. Therefore, the inter-storey drift ratios in high-rise buildings are similar to those of mid-rise buildings at IO for both SMRF and OMRF. Regarding CP, $6 \%$

Table 2. The characteristics of earthquake records selected for IDA.

\begin{tabular}{llccc}
\hline \multicolumn{1}{c}{ Record } & \multicolumn{1}{c}{ Station } & Earthquake date & PGA (g) & Magnitude \\
\hline Chi-Chi Taiwan-03 & CWB99999TCU 129 & $20 / 09 / 1999$ & 0.608 & 6.20 \\
Loma Prieta & UCSC 14 WAHO & $18 / 10 / 1989$ & 0.517 & 6.93 \\
Superstition Hills-02 & USGS 286 Superstition Mtn Camera & $24 / 11 / 1987$ & 0.793 & 6.54 \\
Friuli, Italy-01 & SO12 Tolmezzo & $05 / 06 / 1976$ & 0.346 & 6.50 \\
Victoria, Mexico & UNAMUCSD 6604 Cerro Prieto & $06 / 09 / 1980$ & 0.572 & 6.33 \\
New Zeland-02 & 99999 Matahina Dam & $03 / 02 / 1987$ & 0.293 & 6.60 \\
Northridge-01 & USC 90014 Beverly Hills-12520 Mulhol & $17 / 01 / 1994$ & 0.510 & 6.69 \\
Landers & CDMG 22170 Joshua Tree & $28 / 06 / 1992$ & 0.249 & 7.28 \\
Kobe, Japan & CUE99999 Nishi-Akashi & $16 / 01 / 1995$ & 0.486 & 6.90 \\
Manjil, Iran & BHRC 99999 Abbar & $20 / 06 / 1990$ & 0.505 & 7.37 \\
\hline
\end{tabular}


Table 3. Inter-storey drift angle for IMF [22].

\begin{tabular}{ccc}
\hline \multicolumn{3}{c}{ Interstorey drift angle for IMF } \\
\hline Building height & $\begin{array}{c}\text { Interstorey drift angle } \\
\text { (IO) }\end{array}$ & $\begin{array}{c}\text { Interstorey Drift Angle } \\
\text { (CP) }\end{array}$ \\
\hline Mid rise (4-12 storeys) & 0.015 & 0.09 \\
High rise (>12 storeys) & 0.015 & 0.07 \\
\hline
\end{tabular}

and $8.5 \%$ of inter-storey drift ratios are considered for SMRF and OMRF, respectively in high-rise buildings. No information is mentioned in the relevant codes concerning the Intermediate Moment-Resisting Frames (IMRF) of limit states. Therefore, the values calculated by linear interpolation between inter-storey drift ratios of OMRF and SMRF are assigned to IMRF and are presented in Table 3 [22].

\section{Calculating the response modification factor}

Response modification factor is calculated using incremental dynamic analysis and applying nonlinear static analysis.

\subsection{Basis of calculating Response modification factor}

Uang's method, also known as ductility factor method, is one of the most common methods used for calculating the values of response modification factor [23]. In the mentioned method, nonlinear behavior of structure is modelled with a bilinear relationship and is presented in Figure 4. In this figure, $V_{y}$ and $V_{e}$ are yielding force and maximum base shear, respectively, assuming linear behavior of structures during an earthquake. In Uang's method, $V_{e}$ is reduced to $V_{y}$ because of the ductility and nonlinear behavior of structure. Force reduction factor due to ductility is defined as follows [24]:

$$
R_{\mu}=V_{e} / V_{y} .
$$

Overstrength factor is the ratio of base shear of mechanism $\left(V_{y}\right)$ to the base shear of the first plastic hinge $\left(V_{s}\right)$ defined as follows:

$$
R_{s}=V_{y} / V_{s}
$$

Based on the design codes, $V_{s}$ decreases to $V_{w}$ in the allowable stress design method. The allowable stress factor is defined as follows:

$$
\gamma=V_{s} / V_{w}
$$

In this study, the value of allowable stress factor is considered as 1.44 with respect to the recommendations of UBC-97 [23,24].

Response modification factor is used to convert the linear force applied to the structures into the design

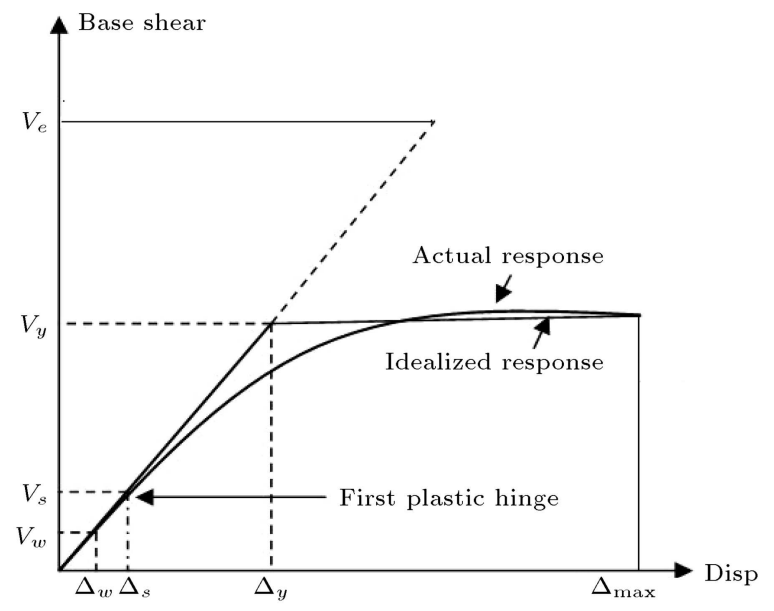

Figure 4. Nonlinear behavior of structure [24].

force, considering the aforementioned discussion. This factor is defined with respect to the ultimate strength and allowable stress design methods and is calculated by Eqs. (4) and (5), respectively [23,24]:

$$
\begin{aligned}
R & =\left(V_{e} / V_{s}\right)=\left(V_{e} / V_{y}\right) \times\left(V_{y} / V_{s}\right)=R_{\mu} \times R_{s}, \\
R & =\left(V_{e} / V_{w}\right)=\left(V_{e} / V_{y}\right) \times\left(V_{y} / V_{s}\right) \times\left(V_{s} / V_{w}\right) \\
& =R_{\mu} \times R_{s} \times \gamma .
\end{aligned}
$$

\subsection{Non-linear static analysis}

Nonlinear static analysis is conducted on the models to assess the base shear corresponding to the first plastic hinge $\left(V_{s}\right)$ and nonlinear behavior of structures. Table 4 presents the values of static base shear equivalent to the first plastic hinge of the structures. Figure 5 also depicts the pushover curves of regular and irregular 16storey frames. In this study, letter A indicates regular reference frames, and letters $\mathrm{B}, \mathrm{C}$, and D denote the irregular frames with mass irregularities located in the first storey, mid-height and roof, respectively.

\section{Calculating the response modification factor using IDA}

Incremental Dynamic Analysis (IDA) is an influential method to predict the capacity and demand of structures. In this technique, the intensity of ground motion measured by IM incrementally increases in each analysis. Drift ratio, an Engineering Demand 
Table 4. Base shears of the first hinge in the regular and irregular models.

\begin{tabular}{ccccc}
\hline \multirow{2}{*}{ No. of storeys } & \multicolumn{4}{c}{$\boldsymbol{V}_{\boldsymbol{s}}$ (ton) } \\
\cline { 2 - 5 } & $\mathbf{A}$ & $\mathbf{B}$ & $\mathbf{C}$ & $\mathbf{D}$ \\
\hline 8 & 74.56 & 77.28 & 76.68 & 75.85 \\
12 & 87.75 & 85.60 & 86.38 & 86.38 \\
16 & 88.24 & 88.24 & 86.92 & 90.69 \\
\hline
\end{tabular}

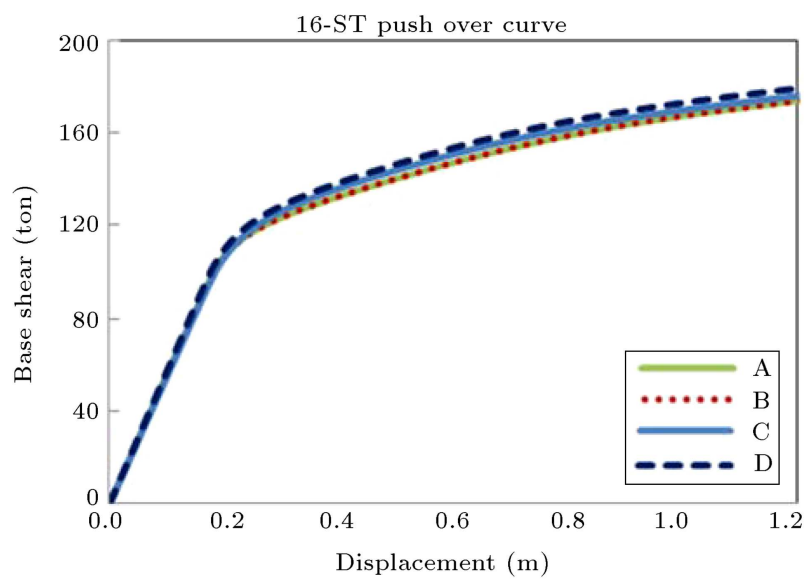

Figure 5. Pushover curves of regular and irregular 16 -storey frames.

Parameter (EDP), is monitored during each analysis. Regarding IM scaling, hunt and fill algorithm was used to optimize the number of scaling of each record based on Eq. (6) [20]:

$$
S a\left(T_{1}\right)_{i}=S a\left(T_{1}\right)_{i-1}+\alpha \times(i-1),
$$

where $S a\left(T_{1}\right)$ is spectral acceleration corresponding to the first mode; $i$ is the number of steps; $\alpha$ is a factor. In this research, $\alpha=0.05$.

Figure 6 presents the IDA curves plotted for regular and irregular models with respect to the aforementioned explanations.

\subsection{Overstrength factor}

Overstrength factor is defined as the ratio of ultimate base shear $\left(V_{b(D y n, y)}\right)$ to the base shear of the first yielding. This method was suggested by Mwafy and Elnashai [25] to obtain maximum base shear through incremental nonlinear dynamic analysis. The method is modified according to the results presented by Massumi et al. [26] and is expressed as follows:

$$
R_{s}=V_{b(D y n, y)} / V_{b(s t, s)},
$$

where $V_{b(D y n, y)}$ is the ultimate base shear; $V_{b(s t, s)}$ is base shear of the first yielding. $V_{b(D y n, y)}$ is the base shear which causes the formation of one plastic hinge in one point of the whole structure. In this research, $V_{b(s t, s)}$ is used instead of $V_{b(D y n, y)}$. If spectral acceleration increases gradually, then only one plastic hinge might be formed in the structure at a time. While only one plastic hinge exists in the whole structure, spectral acceleration may increase up to the initial formation of the second hinge. In this case, the extent of spectral acceleration of the first mode cannot be accurately presented, causing the creation of the first yielding in the structure; besides, its corresponding base shear cannot be calculated. The base shear corresponding to the first plastic hinge formation is derived from nonlinear static analysis and considered as base shear of the first yield for computing the overstrength factor $[25,26]$.

\subsection{Ductility factor}

Spectral acceleration resulting from the formation of mechanism or considered damage is used to obtain maximum nonlinear base shear of the structure $\left(V_{b(D y n, e)}\right)$. It is calculated through dynamic analysis assuming the elastic behavior under the same spectral acceleration. Then, ductility factor is calculated as follows $[25,26]$ :

$$
R_{\mu}=V_{b(D y n, e)} / V_{b(D y n, y)} .
$$

\subsection{Response modification factor}

Overstrength, ductility, and response modification factors are calculated for regular and irregular models with respect to the above discussion and are presented in Table 5 and Figure 7.

Overstrength factor increases by $5-10 \%$ if the heavier storey is located in the first floor of the building (B) compared to that of regular mode (A). The ductility factor decreases by $5-18 \%$ in the case of locating the heavier storey at the first floor (B) and roof level of the building (D), compared to that of (A). Response modification factor generally decreases by $1-21 \%$ in the buildings with mass irregularities,

Table 5. Overstrength, ductility and response modification factors of regular and irregular models.

\begin{tabular}{ccccccccccccc}
\hline & \multicolumn{10}{c}{ Model } \\
\cline { 2 - 13 } & $\mathbf{8 - A}$ & $\mathbf{8 - B}$ & $\mathbf{8 - C}$ & $\mathbf{8 - D}$ & $\mathbf{1 2 - A}$ & $\mathbf{1 2 - B}$ & $\mathbf{1 2 - C}$ & $\mathbf{1 2 - D}$ & $\mathbf{1 6 - A}$ & $\mathbf{1 6 - B}$ & $\mathbf{1 6 - C}$ & $\mathbf{1 6 - D}$ \\
\hline$R_{s}$ & 1.97 & 2.06 & 2.04 & 2.17 & 2.09 & 2.26 & 2.08 & 1.84 & 2.17 & 2.38 & 2.41 & 2.15 \\
$R_{\mu}$ & 2.27 & 2.14 & 2.30 & 1.86 & 2.01 & 1.73 & 1.99 & 1.80 & 1.63 & 1.47 & 1.65 & 1.51 \\
$R_{\text {LRFD }}$ & 4.47 & 4.41 & 4.69 & 4.04 & 4.20 & 3.91 & 4.14 & 3.31 & 3.54 & 3.50 & 3.98 & 3.25 \\
$R_{\text {ASD }}$ & 6.44 & 6.35 & 6.76 & 5.81 & 6.05 & 5.63 & 5.96 & 4.77 & 5.09 & 5.04 & 5.73 & 4.67 \\
\hline
\end{tabular}




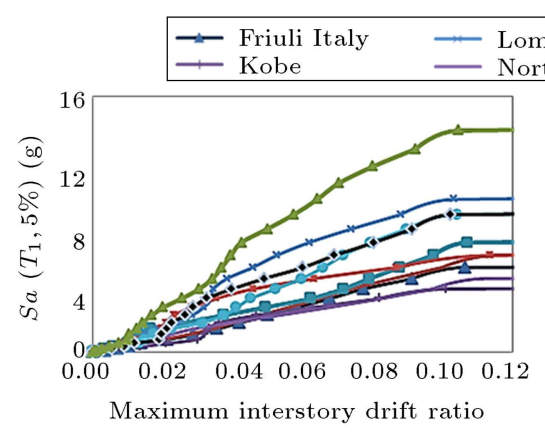

(a)

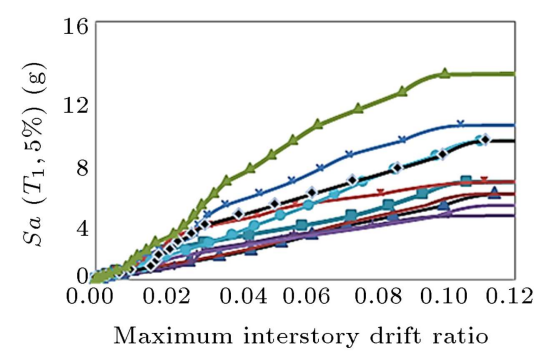

(d)

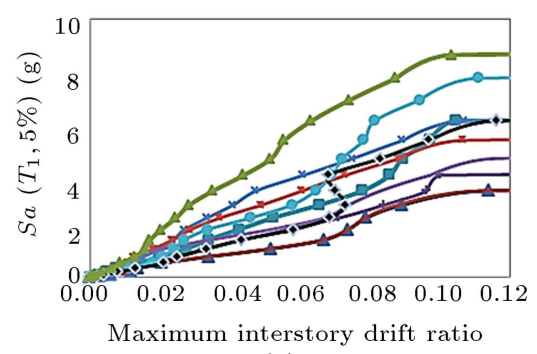

(g)

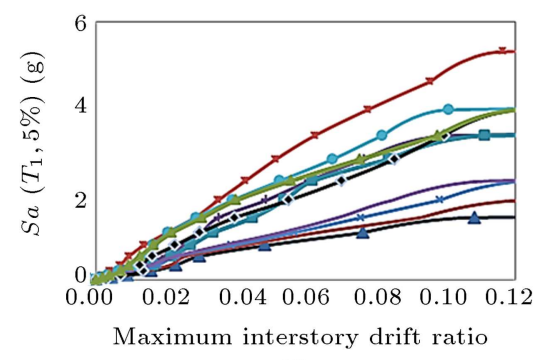

(j)

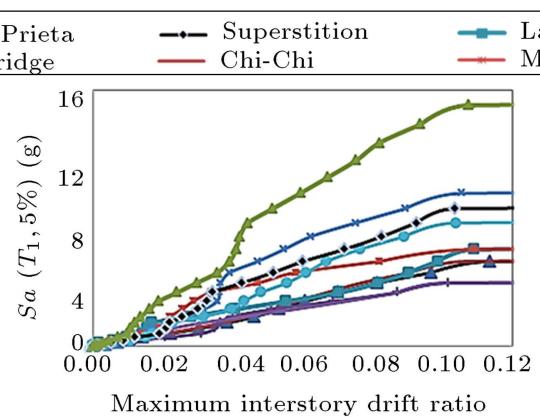

(b)

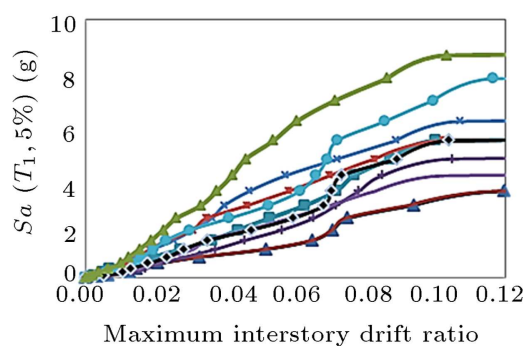

(e)

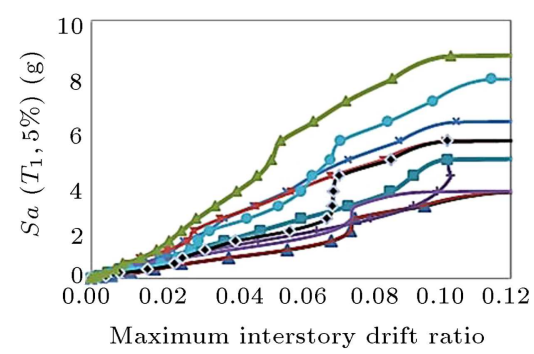

(h)

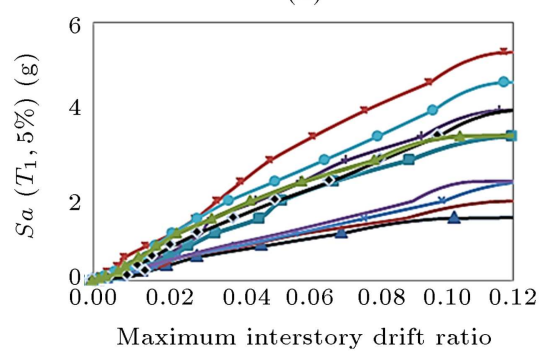

(k)

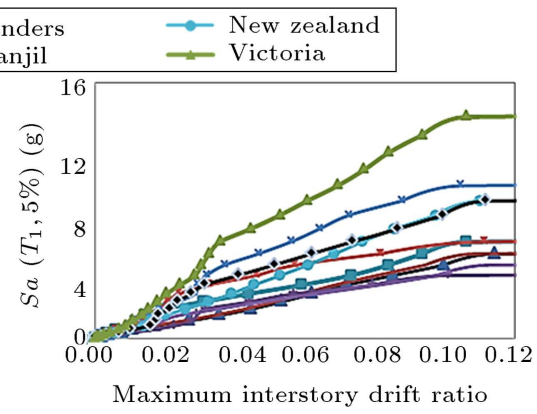

(c)

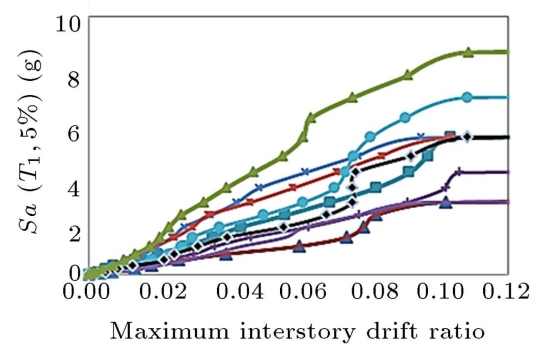

(f)

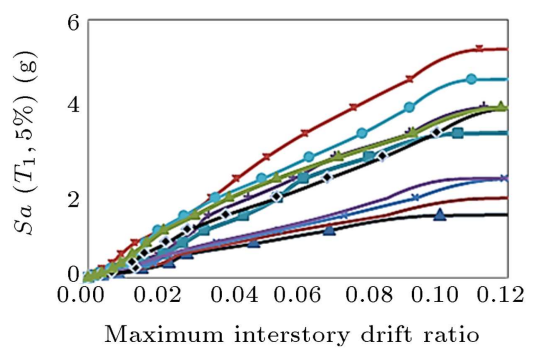

(i)

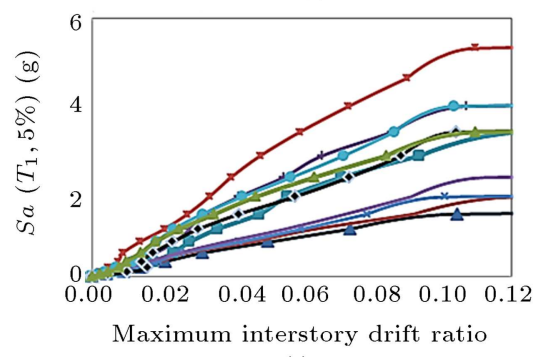

(1)

Figure 6. IDA curves of regular and irregular frames: (a) 8-storey-A, (b) 8-storey-B, (c) 8-storey-C, (d) 8-storey-D, (e) 12-storey-A, (f) 12-storey-B, (g) 12-storey-C, (h) 12-storey-D, (i) 16-storey-A, (j) 16-storey-B, (k) 16-storey-C, and (l) 16-storey-D.

in comparison to that of regular mode. The highest decline rate in the response modification factor occurs in the case where the heavier storey is located at the roof floor. The decrease of ductility is higher in the structures with mass irregularities in the roof floor, compared to the other modes. Regarding a decrease in response modification factor, the ductility capacity can be reduced in such structures with too much mass concentration at a level and, particularly, at the roof floor due to its higher acceleration. While response modification factor of 7 has been suggested in the codes for IMRF, it is reduced with an increase in height in regular and irregular models.

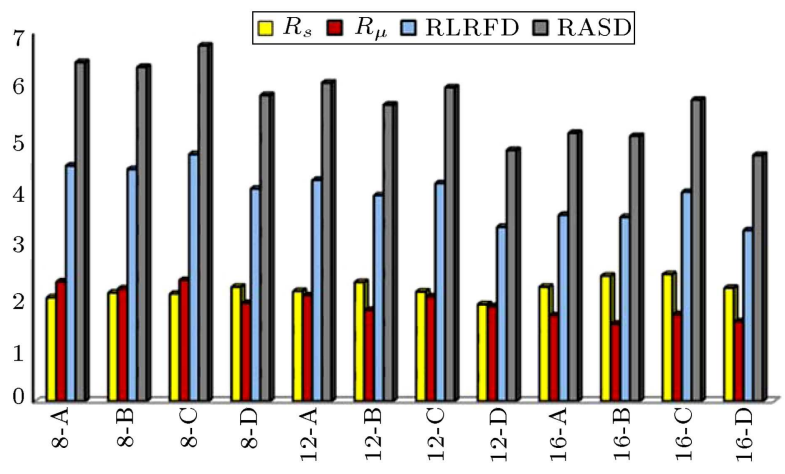

Figure 7. Overstrength, ductility, and response modification factors of the studied models. 


\section{Estimating the probability of occurrence corresponding to the limit states}

In this study, response modification factor is calculated for the structures with mass irregularities in the heights. Then, probabilistic seismicity of any mass irregularity modes is evaluated in different heights. Fragility curves are used to extract the probability occurrence of the limit states from IDA curves. In this way, the probability of occurrence of limit states can be determined at any performance level of the structure for each IM level without considering the seismic hazard, on the condition of the intensity limited to the desired level. Seismic fragility curve, illustrated in Eq. (9), is the conditional probability of exceedance of engineering demand parameter related to the capacity of structure at each damage state under an IM level of ground motion. The researchers suggested different numerical scales, such as PGA, PGV, and $S a\left(T_{1}\right)$, for earthquake intensity $[27,28]$. While the latter is the most ordinarily used scale, PGA and PGV are independent of the structure $[29,30]$ :

$$
\text { Fragility }=P(D \geq C \mid \mathrm{IM}) \text {. }
$$

Fragility curves are generally defined by lognormal cumulative distribution function $[31,32]$ :

$$
P\left(D S \geq d s_{i} \mid S a\left(T_{1}\right)\right)=\phi\left(\frac{\ln X-\mu_{\ln }}{\sigma_{\ln }}\right),
$$

where $P\left(D S \geq d s_{i} \mid S a\left(T_{1}\right)\right)$ is the probability of experiencing or exceeding the damage state $i ; \phi$ is the cumulative standard normal distribution; $X$ is lognormal distribution of spectral acceleration; $\mu_{\ln }$ is the mean variable natural logarithm given by:

$$
\mu_{\ln }=\ln (m)-\frac{\sigma_{\ln }^{2}}{2}
$$

where $m$ is the mean non-logarithmic variables, and $\sigma_{\text {ln }}$ is the standard deviation of variable natural logarithm, defined as follows:

$$
\sigma_{\ln }=\sqrt{\ln \left(1+\frac{s^{2}}{m^{2}}\right)},
$$

where $s$ is standard deviation of non-logarithmic variables. In this research study, earthquake intensity scale $\left(S a\left(T_{1}\right)\right)$ is selected as the elastic spectral acceleration with $5 \%$ damping in the fundamental period of structure. Figure 8 presents the fragility curves of regular and irregular structures for both IO and $\mathrm{CP}$ performance levels.

The discussion presented in Section 5 has been considered to find the degree of collapse prevention and immediate occupancy states of the structures. Table 6

\begin{tabular}{|c|c|c|c|c|c|c|}
\hline \multicolumn{7}{|c|}{ Failure probability (\%) } \\
\hline \multirow[t]{2}{*}{ Model } & \multicolumn{3}{|c|}{$\left(S a_{(T 1,5 \%)}\right)_{I O}(\mathrm{~g})$} & \multicolumn{3}{|c|}{$\left(S a_{(T 1,5 \%)}\right)_{C P}(\mathrm{~g})$} \\
\hline & $16 \%$ & $50 \%$ & $84 \%$ & $16 \%$ & $50 \%$ & $84 \%$ \\
\hline $8-\mathrm{A}$ & 0.50 & 0.80 & 1.28 & 4.00 & 5.92 & 8.76 \\
\hline $8-\mathrm{B}$ & 0.42 & 0.71 & 1.17 & 3.64 & 4.98 & 7.89 \\
\hline $8-\mathrm{C}$ & 0.43 & 0.71 & 1.20 & 5.12 & 5.66 & 8.80 \\
\hline $8-\mathrm{D}$ & 0.38 & 0.63 & 1.01 & 2.74 & 4.34 & 6.86 \\
\hline $12-\mathrm{A}$ & 0.35 & 0.53 & 0.80 & 3.27 & 4.47 & 6.11 \\
\hline $12-\mathrm{B}$ & 0.33 & 0.49 & 0.70 & 2.53 & 3.60 & 5.13 \\
\hline $12-\mathrm{C}$ & 0.33 & 0.50 & 0.75 & 2.73 & 3.95 & 5.72 \\
\hline $12-\mathrm{D}$ & 0.24 & 0.37 & 0.55 & 2.34 & 3.33 & 4.72 \\
\hline $16-\mathrm{A}$ & 0.25 & 0.40 & 0.63 & 1.82 & 2.59 & 3.68 \\
\hline $16-\mathrm{B}$ & 0.17 & 0.32 & 0.58 & 1.53 & 2.21 & 3.21 \\
\hline $16-\mathrm{C}$ & 0.22 & 0.38 & 0.61 & 1.74 & 2.48 & 3.54 \\
\hline $16-\mathrm{D}$ & 0.12 & 0.24 & 0.48 & 1.44 & 2.09 & 3.02 \\
\hline
\end{tabular}
presents the values of $S a$ corresponding to $16 \%, 50 \%$,
Table 6. $S a$ values corresponding to probability of different failures.

and $84 \%$ failures for IO and CP performance levels. According to Figure 8 and Table 6 , the capacity of structures decreases, and the probability of occurrence from a certain damage level augments for both IO and CP performance levels in the irregular buildings, compared to those of regular ones. This fact is more obvious when mass irregularity is located in the first floor and roof levels.

\subsection{Probabilistic Seismic Demand Analysis (PSDA)}

Probabilistic Seismic Demand Analysis (PSDA) is used to calculate the mean annual frequency of exceeding the seismic demand from a certain level in a given structure and designated site [33]. If DM indicates structural demand and IM denotes seismic intensity, probabilistic seismic demand analysis is expressed as follows:

$$
\lambda_{D M}(y)=\int G_{D M \mid I M}(y \mid x) \cdot\left|d \lambda_{I M}(x)\right|,
$$

where $\lambda_{D M}(y)$ is average annual frequency of exceeding $\mathrm{DM}$ from $y$ value (i.e., MAF); $\lambda_{I M}(x)$ is the value of seismic hazard function at point $x$ relative to $I M$ or annual probability of occurrence of certain earthquake intensity; $G_{D M \mid I M}(y \mid x)$ is the probability of DM exceeding $y$, where IM is equal to $x$. The results of probabilistic seismic demand analysis can be used for calculating mean annual frequency, exceeding a certain limit state, usually called $\lambda_{L S}$, defined as follows:

$$
\lambda_{L S}=\int G_{L S \mid D M}(y) \cdot\left|d \lambda_{D M}(y)\right|
$$

where $d \lambda_{D M}(y)$ accounts for the differential of seismic demand hazard with respect to $D M$; in other words, 


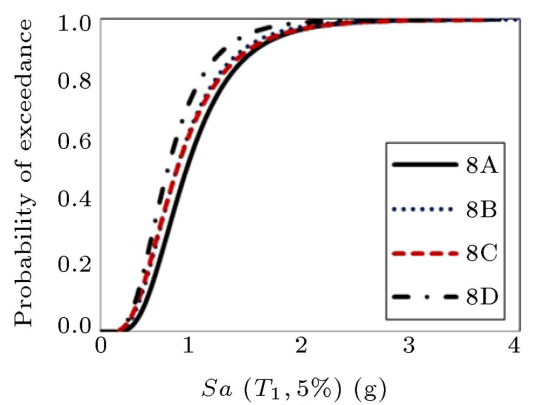

(a)

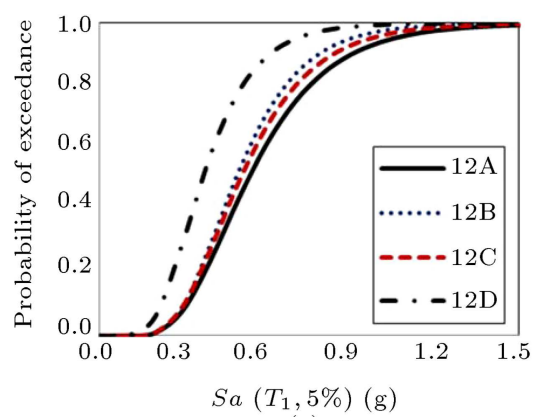

(c)

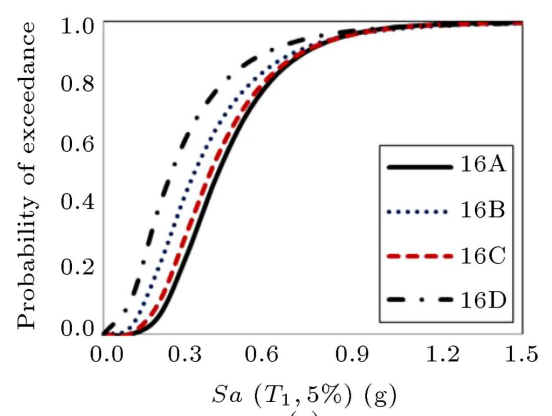

(e)

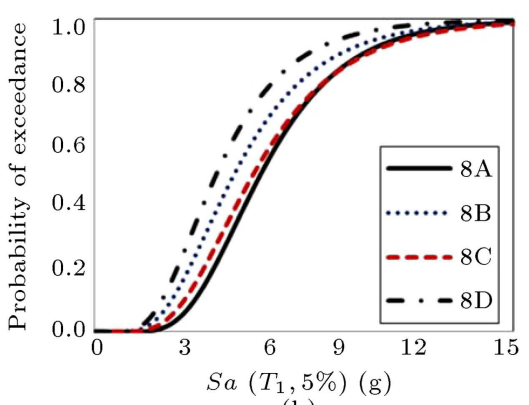

(b)

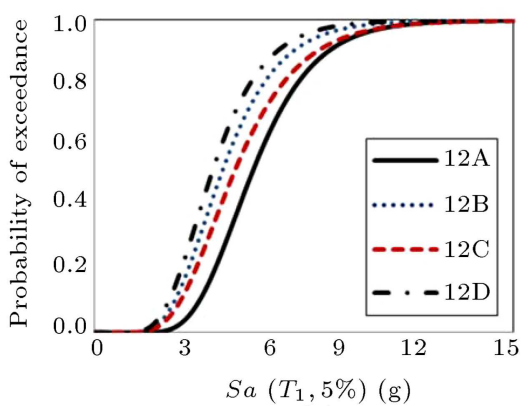

(d)

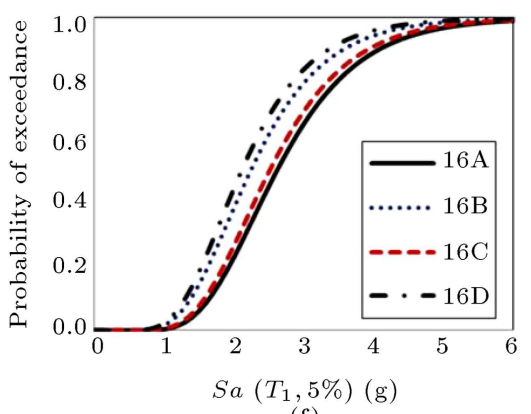

(f)

Figure 8. Fragility curves of regular and irregular structures: (a) 8-storey structure at IO performance level, (b) 8-storey structure at CP performance level, (c) 12-storey structure at IO performance level, (d) 12-storey structure at CP performance level, (e) 16-storey structure at IO performance level, and (f) 16-storey structure at CP performance level.

this phrase determines the annual probability of occurrence of a certain value from $D M . G_{\mathrm{LS} \mid \mathrm{DM}}(y)$ yields the probability of exceeding the limit state $L S$, given that $D M$ is equal to $y$.

Eq. (13) is developed to calculate mean annual frequency of occurrence of limit states as follows [34]:

$$
\lambda_{L S}=\int_{I M=0}^{I M=\infty} F\left(I M^{C} \mid I M\right) \cdot\left|\frac{d \lambda_{I M}}{d I M}\right| d I M,
$$

where the term in the absolute sign is hazard gradient of $I M ; F\left(I M^{C} \mid I M\right)$ is cumulative probability function of limit state occurrence relative to $I M$. This equation is considered as the basis for calculating mean annual frequency of occurrence of limit states.

\section{Seismic demand hazard curves}

Probabilistic seismic demand analysis is ordinarily applied to evaluate the annual frequency of exceeding different limit states. Based on the obtained results, the seismic demand hazard curves are plotted using earthquake return period and spectral acceleration of the fundamental period of structure $\left(S a\left(T_{1}\right)\right)$. These curves are linearly defined on a logarithmic scale and for different earthquake scales $[35,36]$ :

$$
\lambda_{S a\left(T_{1}\right)}(S a)=k_{0}(S a)^{-k},
$$

where $\lambda_{S a(T 1)}(S a)$ is the average annual distribution of $S a\left(T_{1}\right)$ exceeding $S a ; k$ is the slope of seismic hazard curve in the considered capacity; $k_{0}$ is a factor related to the shape of seismic hazard curve. These two parameters can be calculated using seismic hazard curve or simplified hazard spectrum of the region considered with the return periods of 475 and 2475 years. The uniform hazard spectrum for Tajrish in 


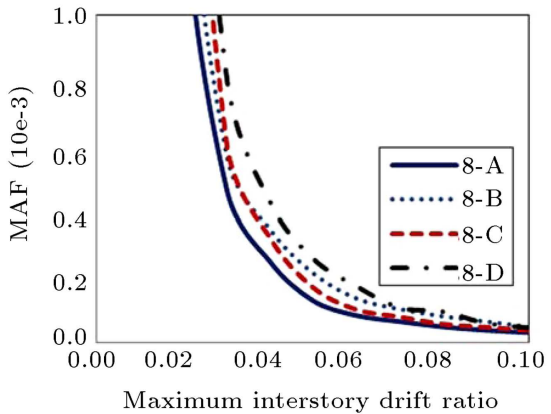

(a)

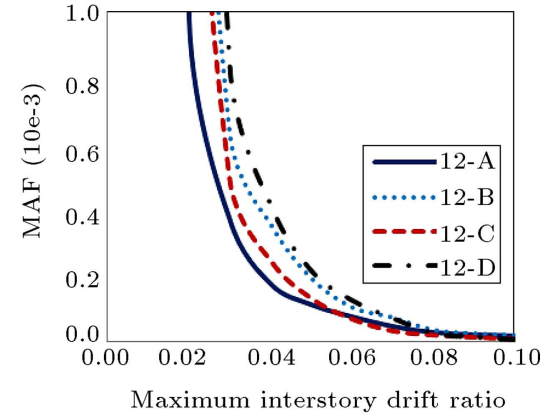

(b)

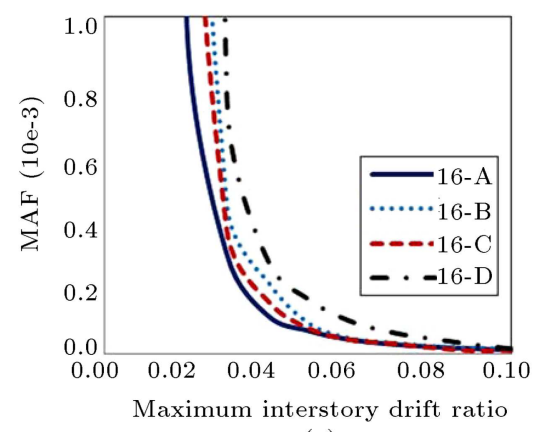

(c)

Figure 9. Seismic demand hazard curves of regular and irregular structures: (a) 8-storey structure, (b) 12-storey structure, and (c) 16-storey structure.

Table 7. Mean Annual Frequency (MAF), return period and probability of once occurrence for all frames at IO and CP performance levels.

\begin{tabular}{|c|c|c|c|c|c|c|c|c|}
\hline \multicolumn{5}{|c|}{ CP performance level } & \multicolumn{4}{|c|}{ IO Performance level } \\
\hline Model & MAF & $\operatorname{Tr}($ year $)$ & $\lambda$ & $\begin{array}{c}\text { Probability of } \\
\text { exceedance of } 2 \% \\
\text { in } 50 \text { years }(\%)\end{array}$ & MAF & $\operatorname{Tr}$ (year) & $\lambda$ & $\begin{array}{c}\text { Probability of } \\
\text { exceedance of } 2 \% \\
\text { in } 50 \text { years }(\%)\end{array}$ \\
\hline $8-\mathrm{A}$ & $3.7 \mathrm{E}-05$ & 27304 & 0.0018 & 0.18 & $3.7 \mathrm{E}-03$ & 271 & 0.18 & 15.33 \\
\hline $8-\mathrm{B}$ & $6.0 \mathrm{E}-05$ & 16660 & 0.0030 & 0.30 & $4.8 \mathrm{E}-03$ & 210 & 0.24 & 18.78 \\
\hline $8-\mathrm{C}$ & $4.6 \mathrm{E}-05$ & 21780 & 0.0023 & 0.23 & $4.3 \mathrm{E}-03$ & 233 & 0.21 & 17.32 \\
\hline $8-\mathrm{D}$ & $6.9 \mathrm{E}-05$ & 14498 & 0.0034 & 0.34 & $5.8 \mathrm{E}-03$ & 173 & 0.29 & 21.61 \\
\hline $12-\mathrm{A}$ & $2.1 \mathrm{E}-05$ & 48600 & 0.0010 & 0.10 & $2.7 \mathrm{E}-03$ & 376 & 0.13 & 11.65 \\
\hline $12-\mathrm{B}$ & $2.5 \mathrm{E}-05$ & 40101 & 0.0012 & 0.12 & $3.2 \mathrm{E}-03$ & 313 & 0.16 & 13.62 \\
\hline $12-\mathrm{C}$ & $2.1 \mathrm{E}-05$ & 46917 & 0.0011 & 0.11 & $2.9 \mathrm{E}-03$ & 346 & 0.14 & 12.49 \\
\hline $12-\mathrm{D}$ & $2.7 \mathrm{E}-05$ & 36450 & 0.0014 & 0.14 & 7.6E-03 & 132 & 0.38 & 25.94 \\
\hline $16-\mathrm{A}$ & $1.7 \mathrm{E}-05$ & 59533 & 0.0008 & 0.08 & $3.5 \mathrm{E}-03$ & 283 & 0.18 & 14.79 \\
\hline $16-\mathrm{B}$ & $2.3 \mathrm{E}-05$ & 44132 & 0.0011 & 0.11 & $7.9 \mathrm{E}-03$ & 127 & 0.39 & 26.59 \\
\hline $16-\mathrm{C}$ & $1.9 \mathrm{E}-05$ & 52465 & 0.0010 & 0.10 & $4.6 \mathrm{E}-03$ & 219 & 0.23 & 18.18 \\
\hline $16-\mathrm{D}$ & $3.0 \mathrm{E}-05$ & 33714 & 0.0015 & 0.15 & $1.3 \mathrm{E}-02$ & 79 & 0.63 & 33.57 \\
\hline
\end{tabular}

the north of Tehran, with the latitude of $35.8^{\circ} \mathrm{N}$ and longitude of $51.42^{\circ} \mathrm{E}$, has been used to evaluate the probabilistic seismic demand of the studied models. Seismic demand hazard curves are plotted for each irregular structure and are compared with those of reference regular ones (see Figure 9).

Poisson probability distribution formula has been applied to calculate the return period $(T r)$ of earthquake corresponding to its probability of occurrence in limit states as well as its probability of occurrence once in 50 years. The obtained results presented in Table 7 are compared with those of Design Base Earthquake (DBE) and Maximum Probable Earthquake (MPE) [37]. If mass irregularities are located in the first floor and roof, the probability of occurrence of one event in 50 years of life expectancy of structures, corresponding to IO performance level, is higher (10\%) than that of DBE with the return period of 475 years. In general, this probability value is higher when the mass is concentrated at the roof floor, compared to that of other states. Therefore, the buildings with the mass concentrated at the roofs have insufficient reliability at IO performance level. Moreover, the probability of 'once occurrence' corresponding to the $\mathrm{CP}$ performance level in 50-year life time of structure is lower (2\%) than that of MPE with the return period of 2475 years, which is equal to the probability of $2 \%$ in 50 years. However, this probability increases in the irregular reference structures, compared with regular ones.

\section{Conclusion}

This study focused on the effects of mass irregularity and its location in height on the behavior of steel MRFs. For this purpose, overstrength, ductility, and response modification factors were calculated through IDA analysis for the structures with mass irregularities. The obtained results were then compared with those of 
reference structures in the regular state. Considering the conditions and soil type of the site, 10 well-known global earthquake records were used to assess the effects of mass irregularity on the seismic performance of steel MRFs through probabilistic seismic demand analysis. Finally, fragility curves and seismic demand hazard curves are plotted for regular and mass irregular structures. Overstrength factor experienced changes in the irregular structures, considering the location of mass irregularity and the concentration of mass in height. The findings are briefly summarized as follows:

1. Overstrength factor increases by $5 \%$ to $10 \%$ in the cases with the mass irregularity in the first floor;

2. No significant change is observed in the overstrength factor in the cases with irregularities in height other than the first floor;

3. Ductility factor decreases by $5 \%$ to $18 \%$ in the cases with the mass irregularity in the first floor and roof;

4. Response modification factor of irregular structures decreases by $1 \%$ to $21 \%$, compared to that of regular ones. This is due to the reduction of ductility factor;

5. The highest decrease in response modification factor occurs when the heavier floor is located at the roof level. Ductility and response modification factors of structure are reduced owing to the excessive mass concentrated at the height, especially at the first floor and roof;

6. The capacity of the irregular structures is reduced in comparison to that of regular ones;

7. The probability of damage is higher in the irregular structures compared to that of the regular ones, considering the fragility curves and $S a$ values corresponding to $16 \%, 50 \%$ and $84 \%$ collapse probabilities for IO and CP performance levels;

8. The probability of damage is higher in the cases with the heavier floor at the roof level. This fact is highly intensified with an increase in height of structure;

9 . The probability of collapse increases in the structures with the heavier floor at the roof level, considering the seismic hazard curves;

10. For both seismic hazard levels of Design Based Earthquake (DBE) and Maximum Probable Earthquake (MPE), poor performance and insufficient reliability of irregular structures at IO performance level are indicated.

\section{References}

1. ATC-3-06, Tentative Provisions for the Development of Seismic Regulations for Buildings, Applied Technology Council (1978).
2. ATC-19, Structural Response Modification Factor, Applied Technology Council (1995).

3. ATC-34, A Critical Review of Current Approaches to Earthquake-Resistant Design, Applied Technology Council (1995).

4. Pirizadeh, M. and Shakib, H. "Probabilistic seismic performance evaluation of non-geometric vertically irregular steel buildings", Journal of Constructional Steel Research, 82, pp. 88-98 (2013).

5. Li, W., Xu, P., Wang, H., and Lu, X. "A new method for calculating the thermal effects of irregular internal mass in buildings under demand response", Energy and Buildings, 130, pp. 761-772 (2016).

6. Sang, W.H., Tae-O, Kim., Dong, H.K., and Seong-Jin, B. "Seismic collapse performance of special moment steel frames with torsional irregularities", Engineering Structures, 141, pp. 482-494 (2017).

7. Valmundsson, E.V. and Nau, J.M. "Seismic response of building frames with vertical structural engineering", ASCE Journal, 123(1),pp. 30-41 (1997).

8. Al-Ali, A. and Krawinkler, H. "Effects of vertical irregularities on seismic behavior of building structures", $\mathrm{PhD}$ Thesis, Blume Earthquake Engineering Center, Stanford University, Stanford, CA (1998).

9. Tremblay, R. and Poncet, L. "Seismic performance of concentrically braced steel frames in multistory buildings with mass irregularity", Journal of Structural Engineering, 131(1), pp. 1363-1375 (2005).

10. Kim, J. and Hong, S. "Progressive collapse performance of irregular buildings", The Structural Design of Tall Special Buildings, 20(6), pp. 721-734 (2011).

11. BHRC, Iranian Code of Practice for Seismic Resistance Design of Buildings, Standard No. 2800-5, 3rd Edition. Building and Housing Research Center (2005).

12. MHUD, Iranian National Building Code, Part 10, Steel Structure Design, Ministry of Housing and Urban Development (2008).

13. AISC-360, Specification for Structural Steel Buildings, American institute of steel construction (2010).

14. FEMA-350, Recommended Seismic Design Criteria for New Steel Moment Frame Buildings, Federal Emergency Management Agency (2000).

15. UBC-97, International Conference of Building Officials, Uniform building Code (1997).

16. Mazzoni, S., McKenna, F., Scott, M.H., Fenves, G.L., and Jeremic, B. OpenSees Command Language Manual, Berkely, CA: Pacific Earthquake Engineering Center, Univ, California at Berkely (2007).

17. Nader, M.N. and Astaneh Asl, A. "Dynamic behavior of flexible, semi-rigid and rigid steel frames", Journal of Constructional Steel Research, 18, pp. 179-192 (1991).

18. Brunesi, E., Nascimbene, R., and Rassati, G.A. "Response of partially-restrained bolted beam-to-column connections under cyclic loads", Journal of Constructional Steel Research, 97, pp. 24-38 (2014). 
19. Brunesi, E., Nascimbene, R., and Rassati, G.A. "Seismic response of MRFs with partially-restrained bolted beam-to-column connections through FE analyses", Journal of Constructional Steel Research, 107, pp. 3749 (2015).

20. Vamvatsikos, D. and Cornell, C.A. "Incremental dynamic analysis", Earthquake Engineering and Structural Dynamics, 31(3), pp. 491-514 (2002).

21. Stewart, J.P., Chiou, S.J., Bray, J.D., Garves, R.W., Somerville, P.G., and Abrahamson, N.A. "Ground motion evaluation procedures for performance based design", Soil Dynamics and Earthquake Engineering, 22, pp. 765-772 (2002).

22. Asgarian, B., Sadrinezhad, A., and Alanjari, P. "Seismic performance evaluation of steel moment resisting frames through incremental dynamic analysis", Journal of Constructional Steel Research, 66, pp. 178-190 (2010).

23. Uang, C.M. "Establishing $\mathrm{R}$ or $(\mathrm{Rw})$ and $\mathrm{Cd}$ factor building seismic provision", Structural Engineering, 117(1), pp. 19-28 (1991).

24. Fanaie, N. and Ezzatshoar, S. "Studying the seismic behavior of gate braced frames by incremental dynamic analysis (IDA)", Journal of Constructional Steel Research, 99, pp. 111-120 (2014).

25. Mwafy, A.M. and Elnashai, A.S. "Calibration of force reduction factors of RC buildings", Journal of Earthquake Engineering, 6(2), pp. 239-273 (2002).

26. Massumi, A., Tasnimi, A.A., and Saatcioglu, M. "Prediction of seismic overstrength in concrete moment resisting frames using incremental static and dynamic analysis", 13th World. Conf. on Earthquake Engineering, Vancouver, B.C, Canada (2004).

27. Cordova, P.P., Deierlein, G.G., Mehanny, S.S.F., and Cornell, C.A. "Development of two-parameter seismic intensity measure and probabilistic assessment procedure", 2nd U.S. - Japan Workshop on Performancebased Earthquake Engineering Methodology for Reinforced Concrete Building Structures, Sapporo, Japan, pp. 187-206 (2001).

28. Hutchinson, T.C., Chai, Y.H., Boulanger, R.W., and Idriss, I.M. "Inelastic seismic response of extended pile-shaft-supported bridge structures", Earthquake Spectra, 20(4), pp. 1057-1080 (2004).

29. Shome, N., Cornell, C.A., Bazzurro, P., and Eduardo, C.J. "Earthquakes, records and nonlinear responses", Earthquake Spectra, 14(3), pp. 469-500 (1998).

30. Luco, N. and Cornell, C.A. "Structure-specific scalar intensity measures for near-source and ordinary earthquake ground motions", Earthquake Spectra, 23(3), pp. 357-392 (2007).

31. Aslani, H. "Probabilistic earthquake loss estimation and loss disaggregation in buildings", PhD Thesis, Department of Civil and Environmental Engineering, Stanford University, Stanford, CA (2005).
32. Wen, Y.K. and Ellingwood, B.R. "The role of fragility assessment in consequence-based engineering", Earthquake Spectra, 21(3), pp. 861-877 (2005).

33. Luco, N., Mai, P.M., Cornell, C.A., and Beroza, G.C. "Probabilistic seismic demand analysis at a near fault site using ground motion simulations based on a stochastic kinematic earthquake source model", 7th Int. Conf. on Earthquake Engineering, Boston, Massachusetts (2002).

34. Porter, K.A. "An overview of peer's performancebased earthquake engineering methodology", 9th Int. Conf. on Applications of Statistics and Probability Civil Engineering (ICASP9), Civil Engineering Risk and Reliability Association (CERRA), San Francisco, CA (2003).

35. Sewell, R.T., Toro, G.R., and McGuire, R.K. "Impact of ground motion characterization on conservatism and variability in seismic risk estimates", Report NUREG/CR-6467, U.S. Nuclear Regulatory Commission, Washington, D.C. (1991).

36. Jalayer, F. and Cornell, C. "A technical framework for probability-based demand and capacity factor design (DCFD) seismic formats", PEER Report 2003/08, Pacific Earthquake Engineering Research Center, University of California, Berkeley (2003).

37. FEMA-356, Prestandard and Commentary for the Seismic Rehabilitation of Buildings, Federal Emergency Management Agency (2000).

\section{Biographies}

Nader Fanaie obtained his BS, MS, and PhD degrees in Civil Engineering from the Department of Civil Engineering at Sharif University of Technology, Tehran, Iran. He graduated in 2008 and, at present, is a faculty member of $\mathrm{K}$. N. Toosi University of Technology, Tehran, Iran. He has supervised 31 MS theses up to now. His field of research includes seismic hazard analysis, earthquake simulation, seismic design and IDA. He has published 40 journal and conference papers, and also 10 books. He received the third place in the first mathematical competition, held at Sharif University of Technology in 1996 and a Gold Medal in "The 4th Iranian Civil Engineering Scientific Olympiad" in 1999. In 2001, he achieved the first rank in the exam of $\mathrm{PhD}$ scholarship abroad. He has also been acknowledged as an innovative engineer on 'Engineering Day' in 2008.

Mohammad Sadegh Kolbadi was born in 1986. He received his MSc degree in Earthquake Engineering from Islamic Azad University, Isfahan (Khorasgan) Branch, Iran in 2015. His field of study is base isolation systems and his research interests include earthquake engineering, seismic evaluation, and retrofitting of building. 